\title{
Anesthetic Management of a Parturient with Congenital Complete Heart Block posted for Emergency Lower Segment Cesarean Section
}

\author{
${ }^{1} \mathrm{R}$ Mamatha, ${ }^{2} \mathrm{MJ}$ Sowmya, ${ }^{3} \mathrm{KT}$ Venkateshmurthy, ${ }^{4} \mathrm{H}$ Sahajananda, ${ }^{5} \mathrm{GS}$ Karthik
}

\begin{abstract}
Pregnancy complicated with complete heart block is rare and usually required termination of pregnancy in the past. Improvement in medical technology in the form of cardiac pacing has allowed taking these women to term. Overall, maternal and fetal outcome is not affected in asymptomatic cases. We report here an unbooked, pregnant patient presented at $38+$ weeks with complete heart block and pregnancy-induced hypertension for emergency lower segment cesarean section (LSCS). Emergency LSCS was performed under general anesthesia. Maternal and fetal outcome was good.
\end{abstract}

Keywords: Complete heart block, Pacemaker, Temporary pacemaker.

How to cite this article: Mamatha R, Sowmya MJ, Venkateshmurthy, Sahajananda H, Karthik GS. Anesthetic Management of a Parturient with Congenital Complete Heart Block posted for Emergency Lower Segment Cesarean Section. J Med Sci 2015;1(4):74-76.

\section{Source of support: Nil}

Conflict of interest: None

\section{INTRODUCTION}

Morquio reported complete heart block (CHB) in the year 1901. He also suggested a familial occurrence. ${ }^{1,2}$ It is one of the conduction disorders in which there is a random relation between atrial and ventricular activation. The incidence of CHB is 1 in 15,000 to 20,000 live births. ${ }^{2,3}$ Its etiology can be idiopathic or autoimmune. Physiologic response to pregnancy causes increase in cardiac output. This is a result of increased heart rate (HR) and blood volume. These alterations do pose a substantial challenge in the patient with a fixed maternal HR. Till date, the management protocols or guidelines for handling these patients are lacking.

${ }^{1}$ Postgraduate Student, ${ }^{2}$ Assistant Professor, ${ }^{3}$ Professor ${ }^{4}$ Professor and Head, ${ }^{5}$ Associate Professor

${ }^{1-5}$ Department of Anesthesia, RajaRajeswari Medical College and Hospital, Bengaluru, Karnataka, India

Corresponding Author: H Sahajananda, Professor and Head Department of Anesthesia, RajaRajeswari Medical College and Hospital, Bengaluru, Karnataka, India, e-mail: sahaj_anand@ hotmail.com
Here, we report an unbooked, pregnant patient presented at $38+$ weeks of gestation with $\mathrm{CHB}$ and pregnancy-induced hypertension (PIH) scheduled for emergency lower segment cesarean section (LSCS).

\section{CASE REPORT}

A 29-year-old female, primigravida at $38+$ weeks came to our hospital with pain abdomen and leaking per vagina. Patient had high blood pressure (BP) readings in her third trimester which was diagnosed as PIH and was put on Tab. Methyl Dopa $250 \mathrm{mg}$ three times a day and Tab. Nicardia $10 \mathrm{mg}$ once daily. She also told the history of having low HR, 8 years ago during regular health checkups. She was advised to consult a cardiologist, which she ignored. She also complained of slight dyspnea and weakness on exertion. She did not complain of syncope, palpitations, or chest pain. On examination, her pulse rate was 41/minute, regular, and BP was 160/100 $\mathrm{mm} \mathrm{Hg}$. Respiratory and cardiovascular systems were normal. Monitoring included electrocardiogram (ECG), pulse oximetry, and noninvasive BP. Emergency cardiac drugs, chemical pacemaker, temporary pacemaker, and C-arm (image intensifier) were made available. We requested the cardiologist to be present for emergency pacing if at all required. Laboratory investigations were found normal. Serological investigations were also normal. A 12-lead ECG (Fig. 1) showed a CHB with an escape rhythm of left bundle branch (LBB) morphology, whereas some QRS

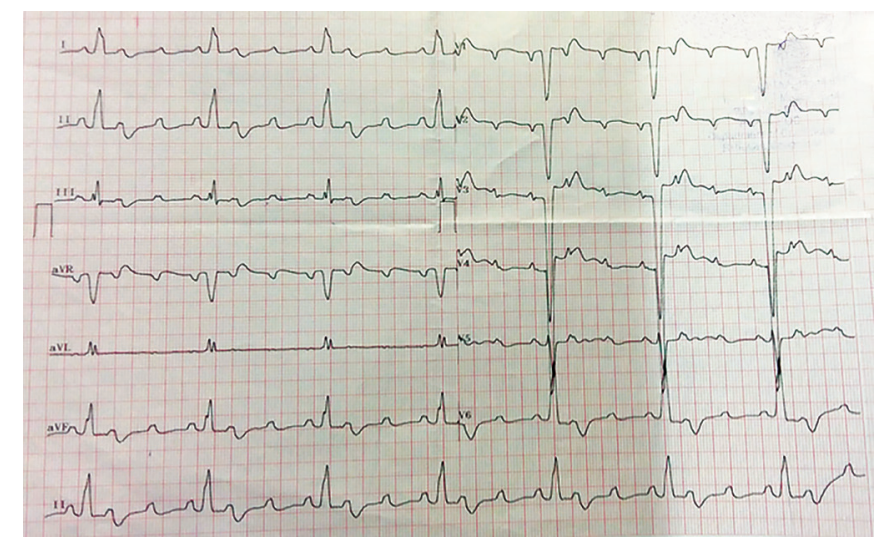

Fig. 1: Electrocardiogram showing $\mathrm{CHB}$ with $\mathrm{LBB}$ and escape beats 
complexes are less wide and one of them is related to atrial activity just preceding it.

In view of her condition and fetal distress, she was scheduled for emergency caesarean section. In the operating room, all the physiological monitors were connected. Her baseline vitals were (Fig. 2): HR - 41 beats/minute, $\mathrm{BP}-160 / 100 \mathrm{~mm} \mathrm{Hg}$, and $\mathrm{SpO}_{2}-100 \%$. The patient was premedicated with Inj. Glycopyrrolate $0.2 \mathrm{mg}$ iv and preoxygenated with $8 \mathrm{~L}$ of $100 \%$ oxygen for 5 minutes. The patient was induced with incremental doses of Inj. Thiopentone $250 \mathrm{mg}$ iv and intubated $6.5 \mathrm{~mm}$ using cuffed Portex endotracheal tube of 6.5 size after giving $0.6 \mathrm{mg} / \mathrm{kg}$ of Inj. Rocuronium iv. General anesthesia was maintained with oxygen + Isoflurane + divided doses of Inj. Rocuronium iv. Intraoperative bradycardia (HR $<30-40$ beats/minute) was treated with chemical pacemaker using Inj. Isoprenaline $0.04 \mathrm{mg}$ slow iv bolus and intermittent doses of $0.01 \mathrm{mg}$ iv (Fig. 3). A single, live, male healthy baby weighing $2.75 \mathrm{~kg}$ was extracted. Multimodal analgesia was administered by using Inj. Paracetamol Ig iv, Inj. Pethidine $50 \mathrm{mg}$ iv, and wound was infiltrated

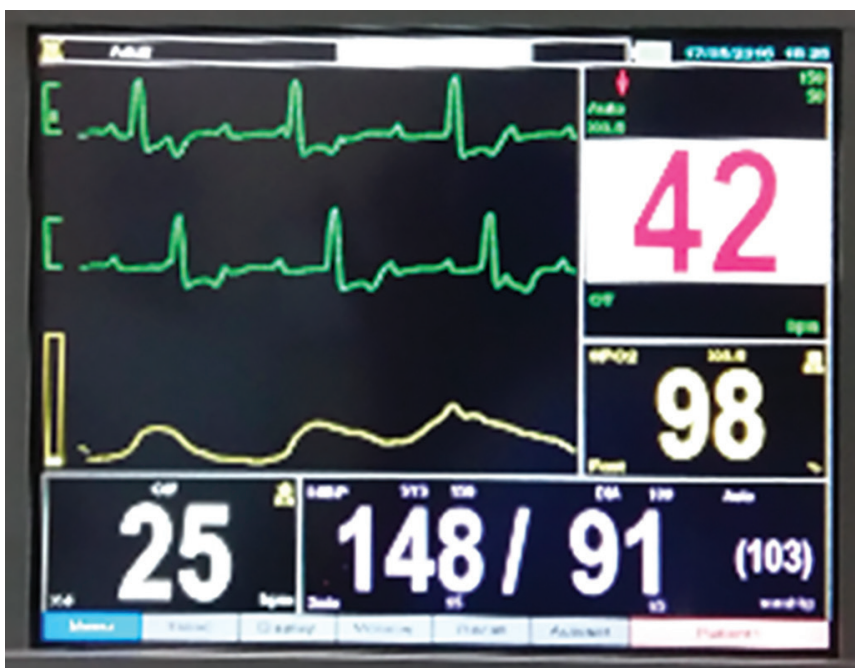

Fig. 2: Monitor tracing showing $\mathrm{HR}$ and $\mathrm{O}_{2}$ saturation before chemical pacemaker

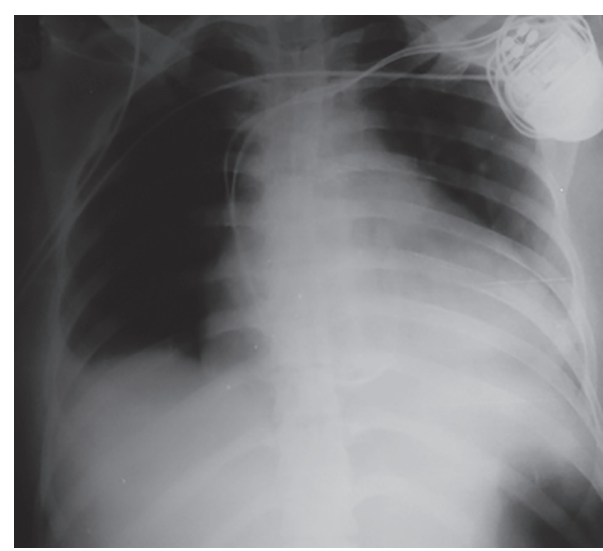

Fig. 4: Permanent pacemaker in place with $10 \mathrm{~mL}$ of $1.5 \%$ Inj. Lidocaine. The intraoperative hypertension was treated with nitroglycerine infusion (NTG) dosage of $0.3 \mathrm{mg} /$ hour. Following completion of surgery, neuromuscular block was reversed with Inj. Glycopyrrolate $10 \mu \mathrm{g} / \mathrm{kg}$ and Inj. Neostigmine $0.05 \mathrm{mg} / \mathrm{kg}$. The patient was extubated after she was awake with adequate muscular tone and power. Then she was shifted to ICU for further evaluation and management.

In the ICU, two-dimensional echocardiography revealed left-ventricular global hypokinasia with ejection fraction of $32 \%$ with adequate right ventricular systolic function. Permanent pacemaker (DDDR - Boston Scientific) was inserted and the HR was set at 100/minute (Figs 4 and 5).

The patient was stable and further course was uneventful. She was discharged on the 7th postoperative day.

\section{DISCUSSION}

The incidence of CHB is rare. It is one of the disorders of cardiac conduction system with the absence of

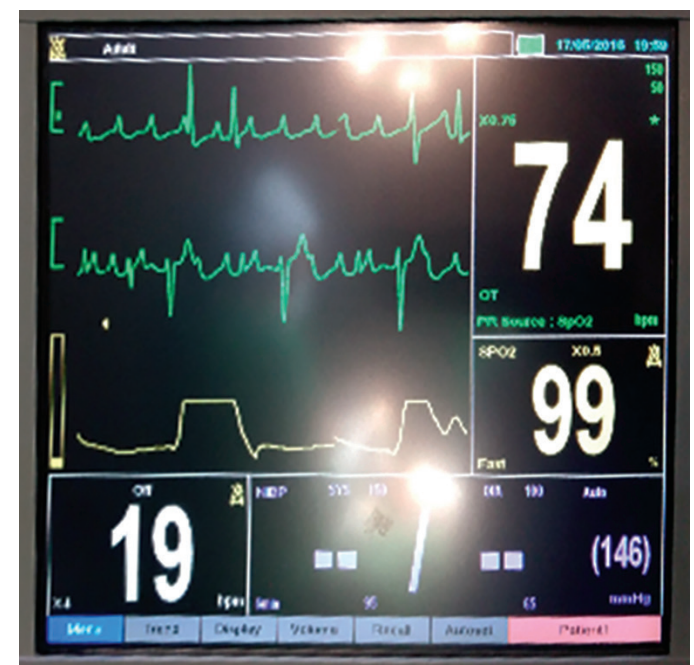

Fig. 3: Monitor tracing showing $\mathrm{HR}$ and $\mathrm{O}_{2}$ saturation after isoprinaline

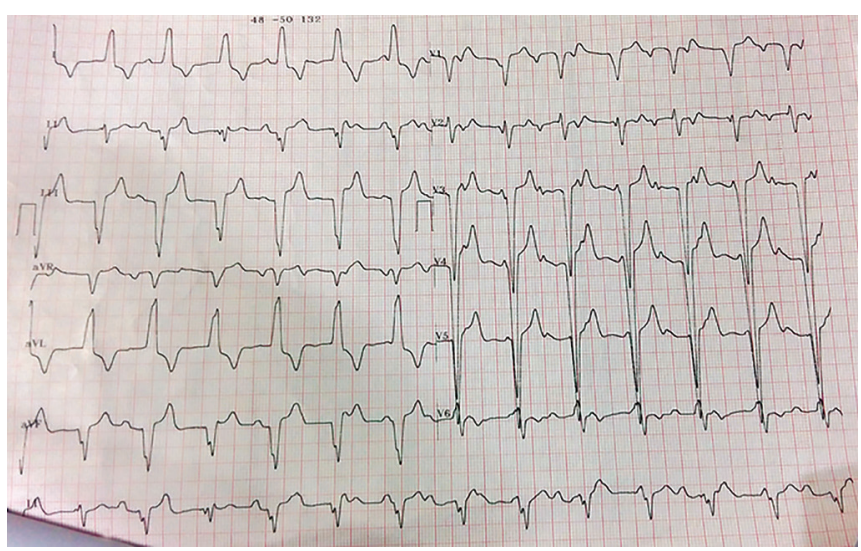

Fig. 5: Electrocardiogram after permanent pacemaker insertion 
conduction between atria and ventricles. The block may be at any location of the conducting system of the heart. It may be at the level of atrioventricular (AV) node, bundle of his or bundle branch or purkinje system. If this is located higher up in septum or in the AV node, the QRS complexes are usually narrow $(<0.15)$ and HR increases in response to exercise, atropine, or sympathomimetic agents. In addition, $30 \%$ of congenital CHBs remain undiscovered until the patient reaches adulthood, and in female patients it may present during any stage of pregnancy. ${ }^{4}$

The causes for the acquired AV conduction blocks can be due to fibrosis of the conduction system, ischemic heart disease, the use of certain negative chronotropic and dromotropic drugs, increased vagal tone, valvular heart diseases, cardiomyopathies, congenital disorders like transposition of the great vessels, electrolyte disturbances, autoimmune diseases, systemic diseases, such as Lyme disease. ${ }^{5,6}$

Our patient probably had a block below the level of $\mathrm{AV}$ node. Pregnancy-induced hypertension complicated her health status. So was treated with Methyl Dopa, which might have worsened her cardiac condition.

Preoperative insertion of pacemaker in pregnant patients is controversial. For symptomatic patients in the first trimester, insertion of permanent pacemaker is the therapy of choice. ${ }^{7}$ It is said that asymptomatic patients who respond to exercise by increase in HR rarely require pacemaker; however, a temporary pacemaker should be available to treat excessive bradycardia or syncope during surgery. ${ }^{8}$ In our patient, the decision to perform a LSCS was taken along with arrangements for a chemical and temporary transvenous pacemaker.

Anesthetic problems in patients with CHB include bradycardia, hypotension, arrhythmias, or cardiac arrest. In order to prevent such complications, anesthetic agents or techniques that do not interfere with HR and conduction are advisable. ${ }^{9}$

Spinal anesthesia is known to produce hemodynamic imbalance and we may not be able to control the level of block. The occurrence of third degree heart block and asystole associated with spinal anesthesia has been reported..$^{10}$ General anesthesia may also have adverse effects due to drugs. Inhalational agents can reduce myocardial contractility and conductivity and sensitize the myocardium to catecholamine. This may in turn reduce cardiac output and lead to arrhythmias. Many complications like bradycardia and asystole have been reported after using opioids like fentanyl and sufentanyl, and the use of suxamethonium, neostigmine, and vecuronium. ${ }^{11,12}$ Propofol can also aggravate heart block. ${ }^{13}$
Increase in stroke volume in the nonpregnant state, results in dilatation of ventricle and which creates a limited capacity to further increase end-diastolic volume and stroke volume. This hemodynamic alteration is unable to cope up with the increase cardiac output in pregnancy. ${ }^{14}$

The use of bupivacaine in epidural anesthesia can affect the conduction system of heart and can worsen the AV block.

We selected and used drugs that do not lead to bradycardia or worsening of heart block. We used continuous ECG monitoring with temporary pacing at hand. We encountered bradycardia on two occasions and treated with Inj. Isoprenaline. As per the cardiologist, patient's cardiac status required a pacemaker in the postoperative period.

To conclude, general anesthesia can be administered without prophylactic transvenous pacing in a case of $\mathrm{CHB}$, provided they are under continuous ECG monitoring with temporary or permanent pacing facilities at hand.

\section{REFERENCES}

1. Morquio L. Sur une maladieinfantile et familialcaractérisée par des modeficationspermanents du pouls, des aattaquessyncopales et epileptiform et al mortsubite. Arch Méd d'Enfants 1901;4:467.

2. Perloff $\mathrm{JK}$. The clinical recognition of congenital heart disease. 5th ed. Philadelphia (PA): Elsevier; 2003.

3. Macado MVL, Tyanan MJ, Curry PVL, Allan LD. Fetal complete heart block. Br Heart J 1988 Dec;60(6):512-515.

4. Reid J, Coleman E, Doig W. Complete congenital heart block. Report of 35 cases. Br Heart J 1982 Sep;48(3):236-239.

5. Zoob M, Smith KS. The aetiology of complete heart block. Br Med J 1963 Nov 9;2(5366):1149-1153.

6. Mukahrji J, DiGrazia J, Galetto D, Vetrovec GW. Lyme carditis. Severe conduction disorder. Mo Med 1990 Feb;87(2):86-88.

7. Mehta S. Goswami D, Tempe A. Successful pregnancy outcome in a patient with complete heart block. J Postgrad Med 2003 Jan-Mar;49(1):98.

8. Modi MP, Butala B, Shah VR. Anesthetic management of an unusual case of complete heart block for LSCS. Indian J Anaesth 2006;50(1):43-44.

9. Mohan VK, Naik AK, Bharti N, Shende D. A patient with congenital complete heart block undergoing multiple exposures to general anaesthesia. Anaesth Intensive Care 2003 Dec;31(6):667-671.

10. Jordi, E-M, Marsch SC, Strebel S. Third degree heart block and asystole associated with spinal anesthesia. Anesthesiology 1998 Jul;89(1):257-260.

11. Clayton D. Asystole associated with vecuronium. Br J Anaesth 1986 Aug;58(8):937-938.

12. Starr NJ, Sethna DH, Estafanous FG. Bradycardia and asystole following the rapid administration of sufentanil with vecuronium. Anesthesiology 1986 Apr;64(4):521-523.

13. James MF, Reyneke CJ, Whiffler K. Heart block following propofol case report. Br J Anaesth 1989 Feb;62(2):213-215.

14. Sullivan JM, Ramanathan KB. Management of medical problems in pregnancy - severe cardiac disease. N Engl J Med 1985 Aug 1;313(5):304-309. 